\title{
Evaluation of freshwater invertebrate sampling methods in a shallow aridland river (Rio Grande, New Mexico)
}

\author{
Ayesha S. Burdett ${ }^{1,2, *}$, Jane S. Fencl ${ }^{1,3}$, Thomas F. Turner ${ }^{1}$ \\ ${ }^{1}$ Department of Biology and Museum of Southwestern Biology, University of New Mexico MSC03 2020, Albuquerque, \\ New Mexico 87131, USA \\ ${ }^{2}$ Present address: New Mexico Museum of Natural History and Sciences, 1801 Mountain Road NW, Albuquerque, \\ New Mexico 87104, USA \\ ${ }^{3}$ Present address: Kansas State University, 205 Leasure Hall, Manhattan, Kansas 66506, USA
}

\begin{abstract}
Aridland rivers can present several logistical challenges for invertebrate sampling due to shifting substrate and low invertebrate densities. We compared 4 sampling methods for collecting both meiofauna and macroinvertebrates in an aridland river (Rio Grande, New Mexico): a water column sampling method, an epibenthic core, a throwtrap, and a stovepipe sampling method. The objective of this study was to find the most efficient combination of sampling methods with which to collect the entire assemblage. Differences were tested among sampling methods in terms of abundance, taxonomic richness, assemblage composition, and invertebrate body size. No single sampling method was able to provide accurate estimates of both abundance and taxonomic richness across the range of body sizes of taxa collected in this study. Invertebrates were concentrated in the epibenthos, and thus using the water column sampling method was not necessary. Samples from the epibenthic core and stovepipe sampling methods contained relatively high densities of small-bodied meiofauna, while throwtrap samples included both meiofauna and macroinvertebrates. Throwtrap and epibenthic core sampling methods together provided the most accurate estimates of taxonomic richness, density, abundance, and invertebrate assemblage composition, and were processed relatively efficiently in the laboratory. Sampling methods that performed well in the Rio Grande are likely to work well in other higher-order $(>4)$ rivers with shifting substrates.
\end{abstract}

KEY WORDS: Sampling method · Aridland river $\cdot$ Meiofauna $\cdot$ Invertebrate size class $\cdot$ Sand bed Microhabitat

\section{INTRODUCTION}

Aridland rivers have been poorly surveyed for invertebrate fauna, partly because sand and silt are difficult to sample quantitatively and are thought to be characterized by low densities of macroinvertebrates (Humphries et al. 1998). However, information about benthic macroinvertebrate communities is important in order to understand ecological processes

\footnotetext{
${ }^{*}$ Corresponding author: ayesha.burdett@state.nm.us
}

such as food web dynamics, turnover rates and water quality in these systems. Arid lands cover roughly $40 \%$ of the earth's surface, and aridland river systems are particularly sensitive to land use and climate changes (Tooth 2000), making their study paramount in understanding and conserving global biodiversity.

Some parts of aridland rivers can have high densities of invertebrate fauna (Pease et al. 2006). In par-

() The authors 2015. Open Access under Creative Commons by Attribution Licence. Use, distribution and reproduction are unrestricted. Authors and original publication must be credited. 
ticular, slow-flowing habitats (such as isolated pools, backwaters and side channels) can have relatively high abundances of potential prey items for small fishes (Thorp et al. 1994), including benthic microcrustacea, rotifers, and early instar insect larvae (Humphries et al. 1999). Furthermore, small invertebrate organisms (meiofauna, 40 to $500 \mu \mathrm{m}$; Palmer et al. 2006) are an important part of the aquatic invertebrate assemblage that can easily be overlooked. Meiofauna often dominate benthic invertebrate assemblages and play important roles in assemblage and ecosystem processes (Palmer et al. 2006), such as providing a food source for larval fishes (King 2004a,b). However, meiofauna are not sampled effectively using traditional sampling methods that focus on the water column (King 2004b).

Other researchers have evaluated the performance and statistical properties of different invertebrate sampling methods, and have concluded that multiple and complementary methods are the most effective way to collect inclusive and representative samples (e.g. Cheal et al. 1993, Turner \& Trexler 1997). Different sampling methods can have advantages for particular habitats and types of invertebrates (e.g. size, mobility), but can also have consistent biases when the goal is to document the entire assemblage of invertebrates over broad spatial scales (Turner \& Trexler 1997). Importantly, the practicalities of sample collection in the field need to be balanced with the efficacy of processing in the laboratory (Feeley et al. 2012).

The Rio Grande in central New Mexico is a large, evulsive river with a sand and silt substrate, and sampling for aquatic invertebrate fauna has rarely been reported here (Pease et al. 2006, Valdez \& Beck 2007, Kennedy 2009, Bixby \& Burdett 2011). This study of sampling method efficiency was conducted as part of a larger study to understand the aquatic food web in the Rio Grande. Four sampling methods were used in parallel to capture invertebrate fauna from specific portions of the whole assemblage. Differences in invertebrate density, taxonomic richness, and assemblage structure were evaluated to determine the performance and bias of each sampling method type, and to recognize overlap among sampling methods. We aimed to select complementary sampling methods that would most accurately represent the whole assemblage. We explicitly tested the null hypothesis that a single sampling method could accurately collect the entire aquatic invertebrate assemblage in slow-flowing habitats of the Rio Grande.

\section{MATERIALS AND METHODS}

Invertebrate assemblages were sampled from June to August 2008 from 5 study locations on the Rio Grande in central New Mexico (Table 1). New Mexico is located in the arid southwestern United States of America. Average annual rainfall in the region is about $23 \mathrm{~cm}$, but inter-annual variation is very high (Weiss et al. 2004).

Cobble and gravel dominated the substrate at the site farthest upstream (Angostura), whereas silt and sand were predominant at 4 downstream sites (Albuquerque, Los Lunas, Sevilleta and Bosque del Apache). Turbidity generally increased downstream from Angostura (range: 20.3 to 66.7 NTU) to Bosque del Apache (range: 1196 to 5176 NTU), largely because of inputs from ephemeral tributaries with silt substrates.

Sites were sampled at 2 wk intervals throughout the summer to incorporate temporal changes in the invertebrate assemblage as part of an ongoing survey at Bosque del Apache. At the other locations, sampling was conducted once during the summer. By sampling at different locations and times, the sampling methods were used for a variety of invertebrate taxa at different life stages and across a range of physical situations (e.g. water depth, substrate composition; Table 1).

At each location and sampling event, samples were collected from 3 sites within slow-flowing areas. Sites were not selected in the main channel, but were limited to isolated pools, backwaters, and side channels (total $=24$ collections). Another study in the Rio Grande has demonstrated that the invertebrate assemblage is concentrated in slower, edge habitats (Bixby \& Burdett 2011).

Four sampling methods were used for collecting both meiofauna and macroinvertebrates (Table 2): a water column sampling method, an epibenthic core, a throwtrap, and a stovepipe sampling method. One sample was collected with each sampling method at each site.

To initiate sampling, the throwtrap and stovepipe samplers were quickly placed into the water and pushed into the top layer of sediment, immediately adjacent to one another ( $50 \mathrm{~cm}$ apart). Water depth was recorded to calculate sample volume. The 4 sampling methods (Table 2) were then used sequentially. (1) Within the throwtrap, the water column sampler was opened and submerged in the water column. The cap was closed, the sampler was lifted out of the water and the contents were poured through a fine-mesh sieve. The water column sampling method was only 


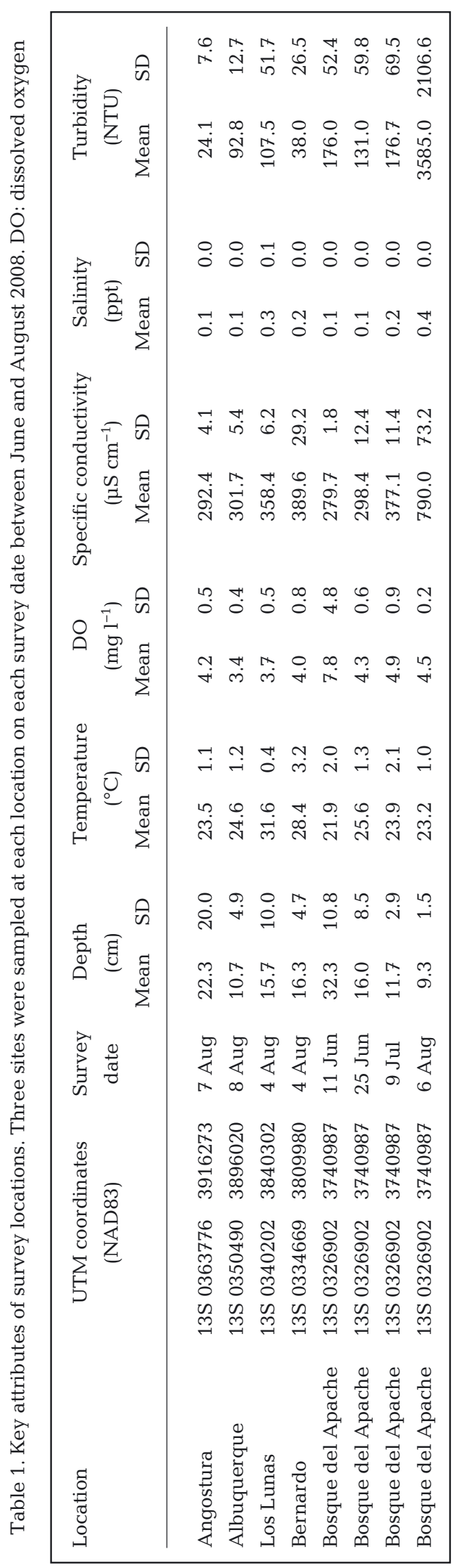

effective in deeper water $(>20 \mathrm{~cm})$ and was limited to 9 samples in this study. (2) Epibenthic core samples were taken from each quadrant of the throwtrap ( $\mathrm{n}=4$ for each sample) by inserting the core into the sediment $(1 \mathrm{~cm})$. A spatula was used to lift the sample out of the throwtrap and into the sieve. Core sampling methods can be useful in sandy substrates because they efficiently sample a uniform area and depth (Gillespie et al. 1985). (3) For the throwtrap sample, a dipnet (500 $\mu \mathrm{m}$ mesh) was used to clear the throwtrap of macroinvertebrates. After each sweep, the contents of the dipnet were emptied into the sieve. A minimum of 3 sweeps were performed within the throwtrap, and sweeps were performed until a thorough visual search yielded no further macroinvertebrates. (4) A hand-operated bilge pump was used to empty the stovepipe sampler. The entire water column and the top layer of sediment were pumped out of the stovepipe sampler and into the sieve.

All contents of the sieve were preserved in the field ( $70 \%$ ethanol) and returned to the laboratory for further processing. The same sieve $(47 \mu \mathrm{m})$ was used for all samples, but washed in between each sample collection to avoid cross-contamination.

In the laboratory, invertebrates were sorted under a stereoscopic microscope. No subsampling was conducted. Invertebrates were identified to Recognizable Taxonomic Units (Oliver \& Beattie 1993). Identification was limited by age of organisms, taxonomic expertise or damage to specimens during collection (in particular, the stovepipe sampler was quite damaging to specimens). Later, specimens were grouped for statistical analyses to reduce bias caused by uneven levels of identification among the samplers. Invertebrates were grouped either to the family level (insect taxa) or to the order level (non-insect arthropods) (Merritt \& Cummins 1995, Smith 2001).

\section{Statistical analyses}

Density (ind. $\mathrm{m}^{-3}$ ) and taxonomic richness (no. taxa sample ${ }^{-1}$ ) were calculated for each sample. Density data were log transformed and 1-way ANOVA was performed to test for differences in density and richness among sampling methods, sample location and sample event (SPSS for Windows v.6.0). Density data was log transformed prior to analysis. All sampling that occurred in August was considered as one 'sample event', and all sampling that occurred at Bosque del Apache throughout the summer was considered as one 'location'. Density data were plotted against taxonomic richness for each sampling method, then 
Table 2. Summary of sampling methods and their attributes. All invertebrate fauna were removed from the sampler and collected in a fine mesh sieve $(47 \mu \mathrm{m})$

\begin{tabular}{|c|c|c|c|c|}
\hline Sampling method & Target organisms & Dimensions & Materials & References \\
\hline Water column & $\begin{array}{l}\text { Free-swimming } \\
\text { meiofauna }\end{array}$ & $\begin{array}{l}7.5 \mathrm{~cm} \text { diam., } \\
30 \mathrm{~cm} \text { length }\end{array}$ & $\begin{array}{l}\text { PVC pipe, } \\
\text { rubber end caps }\end{array}$ & $\begin{array}{l}\text { Greenberg (1964), } \\
\text { Swanson (1978) }\end{array}$ \\
\hline Epibenthic core & $\begin{array}{l}\text { Meiofauna at water- } \\
\text { sediment interface }\end{array}$ & $\begin{array}{l}2.8 \mathrm{~cm} \text { diam., } \\
12 \mathrm{~cm} \text { length }\end{array}$ & $\begin{array}{l}\text { PVC pipe with rubber } \\
\text { flange } 1 \mathrm{~cm} \text { from base }\end{array}$ & King (2004b) \\
\hline Throwtrap & $\begin{array}{c}\text { Macroinvertebrate } \\
\text { fauna }\end{array}$ & $\begin{array}{c}0.25 \mathrm{~m}^{2} \text { base area, } \\
0.7 \mathrm{~m} \text { height }\end{array}$ & $\begin{array}{l}\text { Metal frame covered } \\
\text { with mesh }(250 \mu \mathrm{m}) \\
\text { on vertical sides; } \\
\text { dipnet }(500 \mu \mathrm{m} \text { mesh) }\end{array}$ & Turner \& Trexler (1997) \\
\hline Stovepipe & $\begin{array}{l}\text { Meiofauna and } \\
\text { macrofauna }\end{array}$ & $\begin{array}{l}15.4 \mathrm{~cm} \text { diam., } \\
60 \mathrm{~cm} \text { length }\end{array}$ & $\begin{array}{l}\text { Cylindrical aluminum } \\
\text { pipe; bilge pump }\end{array}$ & Wyss et al. (2013) \\
\hline
\end{tabular}

Pearson's correlation coefficient was calculated across sampling methods.

Assemblage structure was compared among each of the sampling methods to determine if sampling methods were collecting different parts of the assemblage more effectively (PRIMER v.6 for Windows, Primer-E). Three samples were excluded from multivariate analyses because they contained no individuals: epibenthic samples collected at Bernardo and Los Lunas, and a stovepipe sample collected at Albuquerque. ANOSIM was used to determine whether densities and assemblage structure differed significantly among sampling methods (Clarke 1993).

Invertebrate taxa were grouped into classes based on size and mobility (see Table 3 ) to test among sampling methods for potential bias in collecting fauna of different body sizes. Class I was defined as meiofauna, including small bodied organisms such as microcrustacea (0.25 mm maximum body length). Class II invertebrates included most of the insect larvae and annelids, which are primarily benthic, are of similar size ( 0.25 to $5 \mathrm{~mm})$ and have similar means of locomotion. Class III was defined as macrofauna, which were generally highly mobile adult insects (e.g. Corixidae) but also included other large-bodied invertebrate larvae $(>5 \mathrm{~mm})$. Density data of the 3 classes were log transformed and then analyzed using a 1-way ANOVA testing for differences among sampling methods.

\section{RESULTS}

Across the 4 sampling methods, 81 samples were processed that contained 45 taxa (Table 3). Nine samples were processed from the water column sampler and 24 samples were processed from each of the remaining 3 samplers (epibenthic, throwtrap, stovepipe).
The number of invertebrates collected ranged from 0 to 1365 ind. sample ${ }^{-1}$ Despite considerable variation within the sampling methods themselves, invertebrate density and taxonomic richness differed significantly among sampling methods (Table 4, Fig. 1). Throwtrap samples had the lowest densities but the greatest taxonomic richness of any method, whereas epibenthic samples had relatively high densities but low taxonomic richness. Taxonomic richness was lowest in water column samples compared to the other sampling methods. There was also significant spatial and temporal variability identified in invertebrate density and richness. Density and taxonomic richness tended to be greater at Bosque del Apache than other locations; therefore, density and richness were generally greater during the earlier sampling events when the other locations were not included.

Due to different water depths at each sample site, sample volume varied in the throwtrap (41.98 \pm $5.51 \mathrm{l})$ and the stovepipe sampling methods (3.13 \pm 0.41 1). However, there was no correlation between sample volume and invertebrate abundance across the 4 different sampling methods (Pearson correlation, $\mathrm{r}=0.187, \mathrm{p}=0.094$ ). Often, higher abundances were associated with shallow water during drying conditions in the river that concentrated invertebrate populations into smaller areas.

Invertebrate assemblage structure differed significantly among sampling methods despite high levels of variability (ANOSIM: Global $\mathrm{R}=0.121$, $\mathrm{p}<0.001$ ) (Table 5). The differences among groups were modest and had some degree of overlap, but there were significant differences between most of the sampling methods $(p<0.05)$, with the exception of the comparison between epibenthic and stovepipe methods ( $\mathrm{p}=$ 0.476) and the comparison of throwtrap and stovepipe methods $(p=0.092)$. However, all values of $R$ for pairwise ANOSIM comparisons of sampling methods 
Table 3. Invertebrate fauna collected from all locations and survey times (all life stages are combined for the sum totals). A total of 45 taxa were identified from 81 samples. Invertebrate fauna was classified by size and relative mobility: Class I: meiofauna $(<0.25 \mathrm{~mm})$, Class II: insect larvae and annelids (0.25 to $5 \mathrm{~mm})$, Class III: macrofauna $(>5 \mathrm{~mm})$

\begin{tabular}{|c|c|c|c|c|c|c|}
\hline Taxonomic class & sification & Water & Epi- & Throw- & Stove & Total \\
\hline Class I & & & & & & \\
\hline Rotifera & & 2 & 0 & 0 & 0 & 2 \\
\hline Nematoda & & 31 & 821 & 305 & 975 & 2132 \\
\hline Arachnida & Hydracarina & 0 & 2 & 2 & 0 & 4 \\
\hline Crustacea & Cladocera & 71 & 424 & 71 & 504 & 1070 \\
\hline & Copepoda & 74 & 175 & 77 & 272 & 598 \\
\hline & Ostracoda & 2 & 167 & 482 & 445 & 1096 \\
\hline Collembola & Entomobryidae & 0 & 1 & 0 & 1 & 2 \\
\hline & Hypogasturidae & 0 & 0 & 0 & 2 & 2 \\
\hline & Isotomidae & 2 & 0 & 23 & 1 & 26 \\
\hline & unidentified & 0 & 0 & 1 & 1 & 2 \\
\hline Thysanoptera & & 0 & 17 & 17 & 18 & 52 \\
\hline Class II & & & & & & \\
\hline Annelida & Oligochaeta & 1 & 40 & 158 & 36 & 235 \\
\hline & Hirudinea & 0 & 0 & 0 & 1 & 1 \\
\hline Ephemeroptera & Baetidae & 0 & 4 & 161 & 59 & 224 \\
\hline & Heptageniidae & 0 & 2 & 216 & 8 & 226 \\
\hline & Leptohyphidae & 0 & 18 & 1071 & 124 & 1213 \\
\hline Plecoptera & unidentified & 0 & 0 & 0 & 5 & 5 \\
\hline Trichoptera & Hydropsychidae & 0 & 0 & 1 & 2 & 3 \\
\hline & Hydroptilidae & 0 & 0 & 35 & 5 & 40 \\
\hline & Leptoceridae & 0 & 3 & 30 & 3 & 36 \\
\hline Diptera & Ceratopogonidae & e 3 & 95 & 158 & 334 & 590 \\
\hline & Chironomidae & 18 & 368 & 2566 & 767 & 3719 \\
\hline & Empididae & 0 & 0 & 3 & 0 & 3 \\
\hline & Psychodidae & 0 & 0 & 5 & 1 & 6 \\
\hline & Simuliidae & 0 & 0 & 2 & 0 & 2 \\
\hline & Tabanidae & 0 & 0 & 0 & 1 & 1 \\
\hline & Tipulidae & 0 & 0 & 0 & 1 & 1 \\
\hline & unidentified & 0 & 0 & 2 & 0 & 2 \\
\hline Class III & & & & & & \\
\hline Mollusca & Corbiculidae & 0 & 0 & 7 & 5 & 12 \\
\hline & Lymnaeidae & 0 & 1 & 3 & 1 & 5 \\
\hline & Physidae & 0 & 1 & 13 & 4 & 18 \\
\hline Crustacea & Amphipoda & 0 & 0 & 1 & 0 & 1 \\
\hline Odonata & Gomphidae & 0 & 2 & 40 & 1 & 43 \\
\hline & Coenagrionidae & 0 & 0 & 1 & 1 & 2 \\
\hline Hemiptera & Corixidae & 36 & 17 & 1899 & 64 & 2016 \\
\hline & Gerridae & 0 & 0 & 1 & 0 & 1 \\
\hline & Veliidae & 0 & 0 & 2 & 0 & 2 \\
\hline Coleoptera & Carabidae & 0 & 0 & 1 & 0 & 1 \\
\hline & Dytiscidae & 0 & 0 & 5 & 0 & 5 \\
\hline & Heteroceridae & 0 & 0 & 1 & 1 & 2 \\
\hline & Hydraenidae & 0 & 0 & 2 & 0 & 2 \\
\hline & Hydrophilidae & 0 & 0 & 3 & 0 & 3 \\
\hline & Hydrochidae & 0 & 0 & 1 & 0 & 1 \\
\hline & Staphylinidae & 0 & 0 & 2 & 0 & 2 \\
\hline & Stratiomyidae & 0 & 0 & 1 & 0 & 1 \\
\hline $\begin{array}{l}\text { Total } \\
\text { abundance }\end{array}$ & & 240 & 2158 & 7369 & 3643 & 13410 \\
\hline $\begin{array}{l}\text { Total number } \\
\text { of taxa }\end{array}$ & & 10 & 18 & 38 & 30 & 45 \\
\hline
\end{tabular}

were low $(<0.5)$, due to a high level of variability in assemblage composition and high abundances of a few key taxa in all sampling methods (e.g. Chironomidae, Cladocera, Nematoda). Notably, the water column samples usually had very low densities and relatively low taxonomic richness: 6 of the 9 samples contained 5 or fewer individuals and only 10 taxa were collected from all of the water column samples.

\section{Size and mobility classes}

The most abundant taxa collected were Nematoda $(34.9 \%$ of total), Cladocera $(16.9 \%)$, and Chironomidae $(17.2 \%)$. These taxa dominated Class I and Class II defined in this study and were generally most abundant in epibenthic samples and least abundant in water column and throwtrap samples (Fig. 2). There were significant differences among sampling methods in densities of Class II organisms $\left(F_{3,77}=8.34, \mathrm{p}<0.001\right)$, but not of Class I $\left(F_{3,77}=2.42, \mathrm{p}=0.073\right)$ or of Class III $\left(F_{3,77}=2.42, \mathrm{p}=0.072\right)$. There was a trend for densities of Class I organisms to be greater in epibenthic samples than in samples collected with the other 3 sampling methods, but densities in epibenthic samples were extremely variable.

\section{DISCUSSION}

Assemblage composition variability was high, both within and among sampling methods. Some taxa had extremely variable abundances, and some had surprisingly high abundances. For example, the density of chironomids ranged from 0 to $\sim 18000$ ind. $\mathrm{m}^{-3}$, which is higher than found in surveys of braided rivers in New Zealand where total invertebrate density varied from $\sim 900$ to $\sim 5500$ ind. $\mathrm{m}^{-3}$ (Gray \& Harding 2009). High variation among benthic samples is not unexpected: in other surveys of the Middle Rio Grande, the distribution of invertebrate fauna and diatoms was limited by flow velocity and turbidity (Bixby \& Burdett 2011). 
Table 4. Summary of the differences in invertebrate density or taxonomic richness among sampling method, sample event and location. ${ }^{* * *} \mathrm{p} \leq 0.001$; nsd: no significant difference

\begin{tabular}{|c|c|c|c|c|c|c|c|c|}
\hline & \multicolumn{4}{|c|}{ Density } & \multicolumn{4}{|c|}{ Taxonomic richness } \\
\hline & Wald $\chi^{2}$ & df & $\mathrm{p}$ & & Wald $\chi^{2}$ & $\mathrm{df}$ & $\mathrm{p}$ & \\
\hline Method $\times$ sample event & 10.1 & 8 & 0.26 & nsd & 36.1 & 8 & $<0.001$ & $* * *$ \\
\hline Method $\times$ location & 3 & 10 & 0.982 & nsd & 10.6 & 10 & 0.387 & nsd \\
\hline Method & 34.9 & 3 & $<0.001$ & $* * *$ & 125 & 3 & $<0.001$ & $* * *$ \\
\hline Location & 9.2 & 4 & 0.055 & nsd & 33.2 & 4 & $<0.001$ & $* * *$ \\
\hline Sample event & 29.2 & 3 & $<0.001$ & $* * *$ & 104.9 & 3 & $<0.001$ & $* * *$ \\
\hline
\end{tabular}

et al. 2005). Our results indicate that high variation in richness and abundance might be inherent in highly dynamic systems like large aridland rivers, in both spatial and temporal dimensions. Such variability may be important for foraging dynamics of largerbodied consumers such as fish. However, quantification of spatial and temporal variation of inverte-

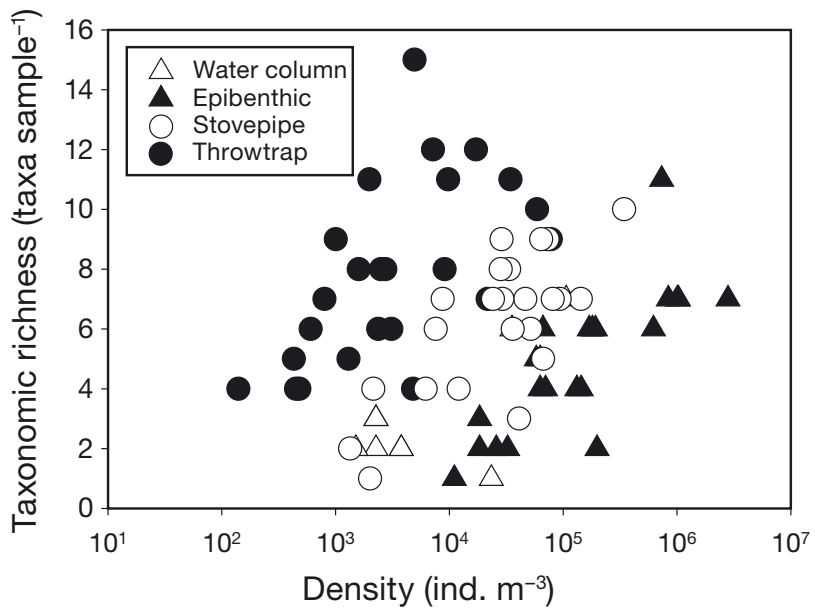

Fig. 1. Total invertebrate density and taxonomic richness from the 4 different sampling methods. Note that density data are presented on a log scale

Table 5. ANOSIM results of invertebrate assemblage structure for each pairwise comparison for the throwtrap, epibenthic, water column, and stovepipe samplers (Global $\mathrm{R}=$ $0.121, \mathrm{p}<0.001) .{ }^{* *} \mathrm{p} \leq 0.01{ }^{* * *} \mathrm{p} \leq 0.001$; nsd: no significant difference

\begin{tabular}{|lrcc|}
\hline Pairwise test & $\mathrm{R}$ & $\mathrm{p}$ & \\
\hline Water column $\times$ epibenthic & 0.234 & 0.009 & ${ }^{* *}$ \\
Water column $\times$ throwtrap & 0.389 & 0.001 & ${ }^{* * *}$ \\
Water column $\times$ stovepipe & 0.420 & 0.001 & ${ }^{* * *}$ \\
Epibenthic $\times$ throwtrap & 0.073 & 0.015 & ${ }^{* *}$ \\
Epibenthic $\times$ stovepipe & -0.005 & 0.476 & nsd \\
Throwtrap $\times$ stovepipe & 0.037 & 0.092 & nsd \\
\hline
\end{tabular}

Similarly, in surveys of the Upper Mississippi (Wisconsin, USA), densities of chironomids were more variable among samples within sites $(40 \%$ of total variance) than among sites within habitats (31\%) (Bartsch et al. 1998). In 2 studies examining spatial hierarchy, variation in benthic invertebrate density was greater among groups of stones within a riffle (53 to $78 \%$ of total variance) than among riffles (0 to $28 \%$ ) in southeastern Australia (Downes et al. 1993, Robson
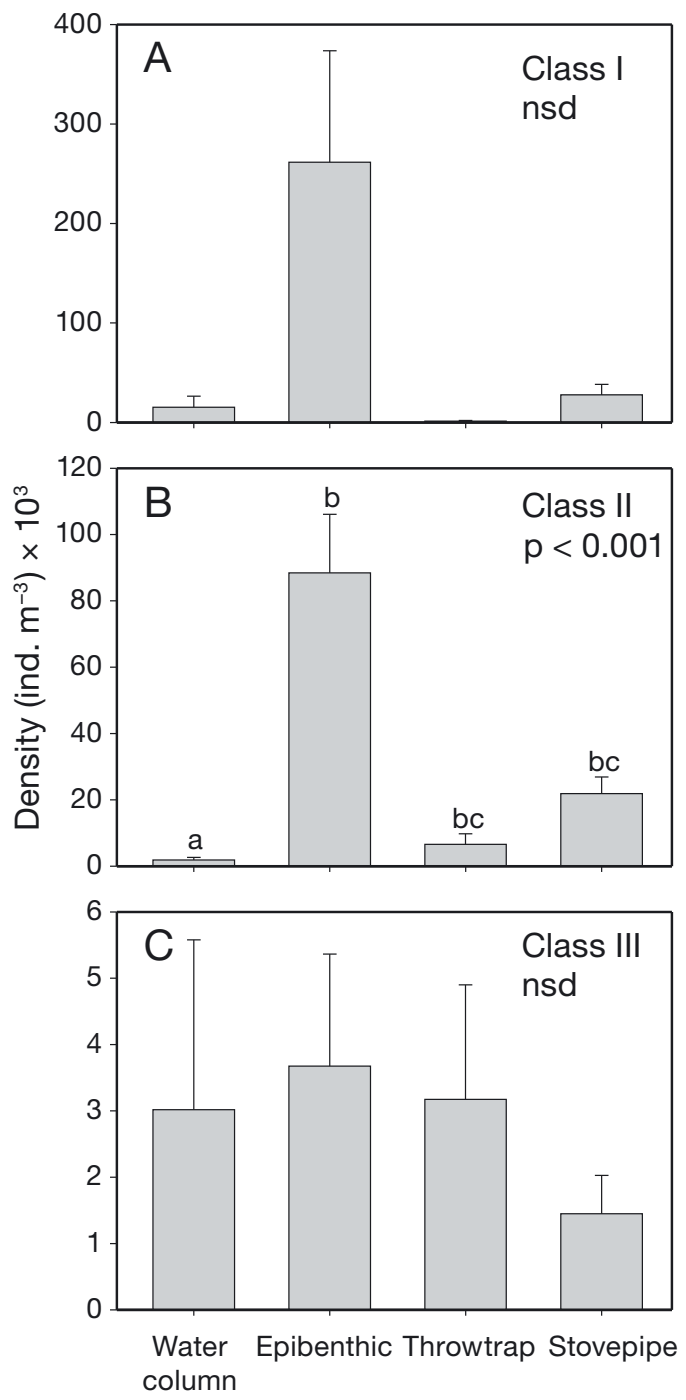

Fig. 2. Mean (+SE) density of invertebrate fauna in the 3 different classes: (A) Class I represents meiofauna $(<0.25 \mathrm{~mm})$; (B) Class II represents larval insects and annelids; (C) Class III represents macrofauna (>5 mm). Note the difference in scale among graphs. Raw data are presented but analyses were performed on log-transformed data. For Class III data, Bonferroni post hoc tests were unable to define significant differences among samplers 
brate distribution is beyond the scope of this study, other than ensuring that sampling was done under a wide variety of conditions.

\section{Comparison of sampling methods}

The stovepipe sampling method did not effectively capture the same richness and density of the aquatic assemblage as the throwtrap and epibenthic sampling methods in combination. Samples collected using the epibenthic core and stovepipe sampling methods had very similar assemblage compositions, suggesting some redundancy of these methods. The epibenthic core collected higher densities of individuals than the stovepipe sampling method, indicating that densities might possibly be underestimated by the stovepipe (particularly of epibenthic meiofauna). The throwtrap collected more species than the stovepipe sampling method, indicating that taxonomic richness may be underestimated by the stovepipe.

Both epibenthic and stovepipe samples had relatively low taxonomic richness compared to throwtrap samples, perhaps as a consequence of differing taxonomic resolution. In general, Class I taxa (meiofauna) were classified at higher taxonomic levels (usually order) than Class III taxa (large insects - usually identified to family). Epibenthic and stovepipe methods were designed to sample the benthos, and therefore captured greater densities of invertebrates that contribute to benthic biomass, especially those taxa assigned to Classes I and II. The epibenthic core samples a relatively small volume or area that could limit its ability to capture Class III taxa (macrofauna); epibenthic cores are useful for sampling less mobile taxa such as chironomids and oligochaetes, but less effective at sampling mobile macroinvertebrates that are able to avoid the sampling mechanism (Cheal et al. 1993).

The dipnet used within the throwtrap was capable of capturing larger and more mobile taxa that could swim away from other stationary sampling methods (i.e. Class III organisms). However, it appears that throwtrap samples underestimate the density of less mobile taxa (Chironomidae, Ceratopogonidae, Nematoda); this may be at least partly due to the coarser mesh of the throwtrap and dipnet $(250 \mu \mathrm{m})$ compared to the sieve mesh. Sampling methods capable of catching most taxa have been found to show the greatest discrimination amongst communities (Cheal et al. 1993); therefore, using the dipnet to clear out the throwtrap is recommended because of its ability to capture high taxonomic richness (cf. comparable 'sweep' sampling method, Turner \& Trexler 1997).

\section{Practicalities}

Several pragmatic advantages of the epibenthic core over the stovepipe sampling method became apparent over the course of the study, both in the field and the laboratory. Although laboratory processing time was not explicitly recorded, clear differences between the 4 sample types were anecdotally reported by research assistants who sorted the samples. (1) Samples were much quicker to collect with the epibenthic core than with the stovepipe sampling method, and effective use of the bilge pump in the stovepipe required considerable experience and skill compared to taking epibenthic cores. (2) Large quantities of sand and silt were often collected in the stovepipe samples, which increased laboratory processing time (c.f. Downing \& Cyr 1985). By contrast, epibenthic core samples were small $\left(6.2 \mathrm{~cm}^{2}\right.$ core $\left.^{-1}\right)$ and sample processing time in the laboratory was shorter (Merritt et al. 1995). Time savings can be particularly important if additional samples are collected in order to improve precision. (3) Invertebrate specimens collected by the stovepipe sampling method were occasionally damaged in the bilging process. For example, gills were often lost from mayfly specimens, making it impossible to identify individuals beyond family. Alternative methods that do not damage specimens and limit taxonomic resolution are preferable to using the stovepipe sampling method (e.g. epibenthic core). (4) Water column samples were easy to collect in the field and easy to process in the laboratory, but the water column sampling method could not be used effectively when water was shallow $(<20 \mathrm{~cm})$. Because water column sampling was spatially and temporally patchy, it was difficult to include these samples in statistical analyses. Additionally, the relatively few invertebrate taxa collected by the water column sampling method added little information to the overall assemblage composition. Densities were substantially lower in water column samples than in epibenthic and stovepipe samples, which indicated that the majority of invertebrates were found in the epibenthos.

\section{CONCLUSIONS}

The study of invertebrate assemblages in large, aridland rivers is partly limited by lack of knowledge about which sampling techniques most effectively provide quantitative sampling in the field and efficient processing in the laboratory. Our study indicates that there is no single sampling method that 
samples the whole assemblage, but that using the throwtrap and epibenthic methods in combination most effectively captured the invertebrate assemblage in the Rio Grande. In particular, this combination of samplers gives insight into diversity and abundance patterns of meiofauna that are chronically understudied in large river systems. These methods were relatively easy to use in the field and are likely to be similarly effective in other higher-order aridland rivers with shifting substrate.

Acknowledgements. Financial support was obtained from National Science Foundation grants DEB-0133233 and DEB0717047 and Tetratech grant T22967. Opinions, findings and conclusions or recommendations expressed in this paper are those of the authors and do not necessarily reflect the views of these agencies. We thank undergraduate research assistants N. Lopez-Brody, L. Kelbe, S. Netz, S. Scholle, and M. Tellez for their assistance in sample collection. L. Kelbe and M. Tellez also helped sort samples and provided invertebrate identifications.

\section{LITERATURE CITED}

Bartsch LA, Richardson WB, Naimo TJ (1998) Sampling benthic macroinvertebrates in a large flood-plain river: considerations of study design, sample size, and cost. Environ Monit Assess 52:425-439

Bixby RJ, Burdett AS (2011) Effects of nutrient availability on periphyton growth and diversity in the Middle Rio Grande: top-down and bottom-up factors. Report to the Middle Rio Grande Endangered Species Act Collaborative Program, USBR, Albuquerque, NM

Cheal F, Davis J, Growns J, Bradley J, Whittles F (1993) The influence of sampling method on the classification of wetland macroinvertebrate communities. Hydrobiologia 257: 47-56

> Clarke KR (1993) Non-parametric multivariate analyses of changes in community structure. Aust J Ecol 18:117-143

> Downes BJ, Lake PS, Schreiber ESG (1993) Spatial variation in the distribution of stream invertebrates: implications of patchiness for models of community organization. Freshw Biol 30:119-132

Downing JA, Cyr H (1985) Quantitative estimation of epiphytic invertebrate populations. Can J Fish Aquat Sci 42: 1570-1579

Feeley HB, Woods M, Baars JR, Kelly-Quinn M (2012) Refining a kick sampling strategy for the bioassessment of benthic macroinvertebrates in headwater streams. Hydrobiologia 683:53-68

- Gillespie DM, Stites DL, Benke AC (1985) An inexpensive core sampler for use in sandy substrata. Freshw Invertebr Biol 4:147-151

Gray D, Harding JS (2009) Braided river benthic diversity at multiple spatial scales: a hierarchical analysis of beta diversity in complex floodplain systems. J N Am Benthol Soc 28:537-551

Greenberg AE (1964) Plankton of the Sacramento River. Ecology 45:40-49

> Humphries P, Growns JE, Serafini LG, Hawking JH, Chick
AJ, Lake PS (1998) Macroinvertebrate sampling methods for lowland Australian rivers. Hydrobiologia 364:209-218 - Humphries P, King A, Koehn J (1999) Fish, flows and flood plains: links between freshwater fishes and their environment in the Murray-Darling River system, Australia. Environ Biol Fishes 56:129-151

Kennedy TL (2009) The effects of stream discharge and channelization on the macroinvertebrate community in a semi-arid landscape. PhD dissertation, University of New Mexico, Albuquerque, NM

King AJ (2004a) Ontogenetic patterns of habitat use by fishes within the main channel of an Australian floodplain river. J Fish Biol 65:1582-1603

> King AJ (2004b) Density and distribution of potential prey for larval fish in the main channel of a floodplain river: pelagic versus epibenthic meiofauna. River Res Appl 20: 883-897

Merritt RW, Cummins KW (eds) (1995) An introduction to the aquatic insects of North America, 3rd edn. Kendall/Hunt Publishing, Dubuque, IA

Merritt RW, Resh VH, Cummins KW (1995) Design of aquatic insect studies: collecting, sampling and rearing procedures. In: Merritt RW, Cummins KW (eds) An introduction to the aquatic insects of North America, 3rd edn. Kendall Hunt Publishing, Dubuque, IA, p 12-28

> Oliver I, Beattie AJ (1993) A possible method for the rapid assessment of biodiversity. Conserv Biol 7:562-568

Palmer MA, Strayer DL, Rundle SD (2006) Meiofauna. In: Hauer FA, Lamberti GA (eds) Methods in stream ecology. Academic Press, San Diego, CA, p 415-433

Pease AA, Davis JJ, Edwards MS, Turner TF (2006) Habitat and resource use by larval and juvenile fishes in an aridland river (Rio Grande, New Mexico). Freshw Biol 51: 475-486

Robson BJ, Hogan M, Forrester T (2005) Hierarchical patterns of invertebrate assemblage structure in stony upland streams change with time and flow permanence. Freshw Biol 50:944-953

Smith DG (2001) Pennak's freshwater invertebrates of the United States: Porifera to Crustacea, 4th edn. John Wiley \& Sons, New York, NY

> Swanson GA (1978) A water column sampler for invertebrates in shallow wetlands. J Wildl Manag 42:670-672

Thorp JH, Black AR, Haag KH, Wehr JD (1994) Zooplankton assemblages in the Ohio River: seasonal, tributary, and navigation dam effects. Can J Fish Aquat Sci 51: 1634-1643

> Tooth S (2000) Process, form and change in dryland rivers: a review of recent research. Earth Sci Rev 51:67-107

> Turner AM, Trexler JC (1997) Sampling aquatic invertebrates from marshes: evaluating the options. J N Am Benthol Soc 16:694-709

Valdez RA, Beck SE (2007) Documentation and quantification of food types available to the Middle Rio Grande fish community, New Mexico (2005-2006). Report to the Middle Rio Grande Endangered Species Collaborative Program, New Mexico Interstate Stream Commission, Santa Fe, NM

> Weiss JL, Gutzler DS, Allred Coonrod JE, Dahm CN (2004) Seasonal and inter-annual relationships between vegetation and climate in central New Mexico, USA. J Arid Environ 57:507-534

Wyss LA, Dugger BD, Herlihy AT, Gerth WJ, Li JL (2013) Effects of grass seed agriculture on aquatic invertebrate communities inhabiting seasonal wetlands of the southern Willamette Valley, Oregon. Wetlands 33:921-937 